\title{
CARTOGRAFIA SOCIOCULTURAL DE ESPAÇOS E PRÁTICAS EDUCATIVOS AMERÍNDIOS: REFLETINDO SOBRE A INDIGENIZAÇÃO DA ESCOLA
}

SERGIO BAPTISTA DA SILVA ${ }^{1}$

UFRGS

\begin{abstract}
RESUMO: $O$ artigo tem por objetivo relatar e refletir sobre uma experiência do autor como ministrante da disciplina de Metodologia da Pesquisa no Curso de Especialização em Educação Profissional integrada à Educação Básica na Modalidade Educação de Jovens e Adultos - Proposta diferenciada para indígenas (PROEJA INDÍGENA), na Universidade Federal do Rio Grande do Sul. O relato enfoca basicamente o momento de discussão e construção de instrumentos metodológicos qualitativos para cartografar espaços e práticas educativos em terras indígenas, com os quais se tem o intuito de contribuir para uma indigenização da escola ameríndia, e promover a introdução de suas sócio-cosmo-ontologias nos processos escolares.
\end{abstract}

PALAVRAS-CHAVE: Cartografia Sociocultural; espaços e práticas educativos; educação escolar indígena; indigenização da escola ameríndia; kaingang; mbyá-guarani.

ABSTRACT: The article aims to report and reflect on the author's experience as a lecturer on Research Methodology as a subject of the Specialization Course in Professional Education Integrated to Basic Education - Youth and Adults Education - Differentiated proposal for indigenous (PROEJA INDÍGENA) at the Federal University of Rio Grande do Sul. The report focuses primarily on the discussion and construction of qualitative methodological tools for mapping spaces and educational practices in indigenous lands, with which it's intended to contribute to the indigenization of Amerindian schools and promote the introduction of their socio-cosmo-ontologies in educational processes.

KEYWORDS: Sociocultural Cartography; educational spaces and practices; indigenous education; indigenization of Amerindian schools; kaingang; mbyá-guarani.

\footnotetext{
${ }^{1}$ Professor no Departamento e no Programa de Pós-graduação em Antropologia Social da UFRGS. Coordenador do Núcleo de Antropologia das Sociedades Indígenas e Tradicionais (NIT-UFRGS).E-mail: sergiobs@terra.com.br.
}

Espaço Ameríndio, Porto Alegre, v. 7, n. 2, p. 227-238, jul./dez. 2013. 
SERGIO BAPTISTA DA SILVA - Cartografia sociocultural de espaços e práticas educativos...

\section{Introdução}

O artigo relata uma experiência particular do autor como ministrante, juntamente com o historiador kaingang Danilo Braga, da disciplina de Metodologia da Pesquisa no Curso de Especialização em Educação Profissional integrada à Educação Básica na Modalidade Educação de Jovens e Adultos - Proposta diferenciada para indígenas (PROEJA INDÍGENA), no período de 2010 a 2012, realizado na Faculdade de Educação da Universidade Federal do Rio Grande do Sul e coordenado por Maria Aparecida Bergamaschi e Tania B. I. Marques. Este relato enfoca basicamente o momento de discussão e construção de instrumentos metodológicos qualitativos para cartografar espaços e práticas educativos em terras indígenas.

Inspirado nos recentes e novos rumos no Brasil da Cartografia Social ou Nova Cartografia, especialidade da área cartográfica que empodera coletivos tradicionais na medida em que lhes proporciona técnicas e métodos para autocartografar e autodefinir seus territórios, e especialmente tocado pelo trabalho de Alfredo Wagner Berno de Almeida (Programa Nova Cartografia Social da Amazônia, cujos objetivos principais são os de mapear e identificar grupos sociais pouco conhecidos, dando-lhes visibilidade, no que diz respeito à sua história, conflitos e reivindicações), fiz a opção de desenhar junto com os participantes do Curso (a quem expresso meus agradecimentos pelo empreendimento coletivo), que abrangia tanto professores indígenas principalmente kaingang e mbyá-guarani - como gestores não indígenas, uma Cartografia Sociocultural de espaços e práticas educativos presentes em terras indígenas, para além do espaço escolar (r)estrito.

Tive como objetivo valorizar seus saberes e conhecimentos e contribuir para a orientação de políticas públicas que tenham a intenção de levar as lógicas indígenas para a escola, promovendo-as e simetrizando-as aos conhecimentos eurorreferenciados.

Assim, expandi o conceito de cartografar para além de espaços territorialmente visíveis, incorporando outros espaços da cultura, como a cosmologia e a ontologia (BAPTISTA DA SILVA, 2002 e 2013), para 
SERGIO BAPTISTA DA SILVA - Cartografia sociocultural de espaços e práticas educativos...

definir espaços e práticas educativos tradicionais indígenas.

Neste sentido, optou-se pela confecção (e futura utilização) destes instrumentos etnográficos através de procedimentos participativos, nos quais os cursistas indígenas se apropriaram de tais ferramentas metodológicas, com o objetivo de contribuir para a construção e constituição de sujeitos políticos autônomos que o são, e a afirmação de seus saberes e de suas identidades, que se autodefinem e têm existência coletiva, favorecendo, com isto, a formação de pesquisadores indígenas e de suas contribuições particulares para as reflexões sobre estrutura curricular, práticas pedagógicas e gestão escolar. Em outras palavras, tem-se como objetivo principal uma "indigenização da escola", parodiando a expressão "indigenização da modernidade" de Marshal Sahlins (1997a e 1997b), como, de uma certa forma, já o fizeram Carneiro (2013) e Rosa e Nunes (2013).

Se a Nova Cartografia Social possibilitou ferramentas metodológicas para os coletivos tradicionais produzirem mapas e monitorarem seus territórios, espero que a presente proposta de Cartografia Sociocultural possa oferecer instrumentos etnográficos para uma autocartografia dos espaços e práticas educativos indígenas, pesquisando e visibilizando os processos histórico-culturais da escola indígena em suas Tls e contribuindo para a compreensão, introdução e promoção de suas sócio-cosmo-ontologias nos processos escolares.

Espero que a compreensão, a valorização e a legitimação destes espaços e práticas contribuam para a indigenização da escola em TIs, visibilizando suas especificidades cosmo-ontológicas, combatendo preconceitos, e, como consequência, promovendo a permanência dos estudantes indígenas nas escolas.

1. Construindo instrumentos metodológicos qualitativos para cartografar espaços e práticas educativos e pesquisar sobre processos de educação escolar e histórias sobre a educação escolar em Tls

Como já dito, os instrumentos metodológicos que seguem são fruto de um trabalho conjunto, dialógico e reflexivo, empreendido pela turma de alunos do PROEJA INDíGENA 2010-2012, realizado nos 
SERGIO BAPTISTA DA SILVA - Cartografia sociocultural de espaços e práticas educativos...

seminários de Metodologia da Pesquisa, durante a Etapa 4 - setembro de 2011 , com participação do componente curricular Processos Próprios de Aprendizagem, quando foram listados e, em alguns casos, brevemente caracterizados os espaços e práticas a serem trabalhados pelos alunos em formação, com algumas indicações ou perguntas reflexivas, o que dá aos instrumentos um tom telegráfico, indagativo e aberto.

Seguindo uma proposta de pesquisa qualitativa, amplamente utilizada em Antropologia, eles foram pensados e construídos participativamente, com o sentido de auxiliar e apoiar os trabalhos de campo que serão desenvolvidos com dois objetivos principais:

$1^{\circ}$. - o de empreender uma Cartografia Sociocultural dos espaços e práticas educativos que ocorrem em terras indígenas no Rio Grande do Sul, identificando-os, inventariando-os e refletindo sobre estes espaços e práticas, e

$2^{\circ}$. - o de levantar, registrar e refletir a respeito dos processos de educação escolar indígena, enfocando alguns elementos característicos de suas constituições e histórias em terras indígenas previamente escolhidas.

Os instrumentos de pesquisa ora apresentados devem ser encarados como propiciadores de um diálogo inter e transcultural, que enfatiza e valoriza o "encontro etnográfico" entre os dois sujeitos que o constituem. Neste sentido, os elementos neles listados devem ser compreendidos como roteiros ou guias para a observação participante, para a entrevista aberta e para o levantamento de histórias de vida, não se constituindo absolutamente em perguntas fechadas e restritivas do diálogo e do encontro que se quer estabelecer. Seguindo esta lógica, os próprios espaços e práticas educativos aqui listados não devem ser considerados como exaustivos: o campo e a interlocução vai alargar sua abrangência.

As técnicas de registro deste "encontro" devem ser avaliadas conforme seu contexto, pesadas as questões éticas e de constrangimento da interlocução. Dentre elas, destacamos o uso do diário de campo, o registro de imagens (fotografias e vídeos) e a gravação sonora.

Por outro lado, a linguagem não coloquial, por vezes acadêmica, 
com a qual eles foram escritos deve ser constantemente adaptada aos contextos particulares de pesquisa que serão enfrentados, objetivando estabelecer e evidenciar contextos os mais simétricos possíveis, a lógica principal da metodologia que se está pretendendo empregar. Aconselha-se, quando possível, o uso do idioma nativo e/ou as categorias próprias do coletivo indígena trabalhado, utilizando termos ou expressões da sua língua.

Uma última palavra deve ser dita quanto aos potenciais interlocutores e contextos de pesquisa. Objetivando alcançar uma polifonia, uma multiplicidade de informações e de pontos de vista, recomendamos que cada aluno(a)-pesquisador(a) diversifique sua interlocução, observando/entrevistando não apenas homens ou lideranças políticas ou adultos ou anciães, mas, também, mulheres, crianças, jovens, lideranças religiosas, etc. Cada observação/entrevista/história de vida deve conter o registro dos principais dados de identificação do interlocutor (nome, nome indígena, patrimetade, idade, local de nascimento, locais anteriores de residência, local e data da pesquisa, etc.), dos pesquisadores e informações sobre o contexto da interlocução (inserção, imersão, espacialidade, participantes, aspectos intersubjetivos, interação, constrangimentos, etc.).

\subsection{Cartografia Sociocultural dos Espaços e Práticas Educativos}

\subsubsection{Espaços educativos (onde se aprende?, o quê?, com quem?, como?)}

\section{Casa}

Há uma falsa ideia de que o aluno indígena não tem conhecimentos anteriores a ser explorados. Os currículos aplicados nas escolas indígenas apresentam lacunas (contagem até 10, por exemplo). Os inúmeros aspectos anteriores de aprendizagem devem ser registrados e valorizados. Exemplos: coleta de matéria prima; contagem; tempo da coleta; confecção do artesanato; vivência com os mais velhos; 
SERGIO BAPTISTA DA SILVA - Cartografia sociocultural de espaços e práticas educativos...

brincadeiras com crianças mais velhas; brincadeiras sem tempos marcados; autonomia das crianças; cuidados dos mais velhos com seus irmãos; convívio com o coletivo; espaço de oralidade; espaço doméstico/feminino e seus papéis de aconselhamento e posicionamento crítico e político (Associação de Mulheres); papel da mãe/mulher na educação e nas práticas com os filhos/as crianças; os vários papéis desempenhados pelas mulheres nas várias atividades deste espaço doméstico (colheita, afazeres da casa, confecção e venda do artesanato,...); etc. A criança aprende observando. As experiências na comunidade, na família.

\section{Espaços de venda do artesanato}

Registrar e refletir sobre estes espaços de vivência e convivência.

\section{Mata}

Observar e entrevistar sobre as práticas e conhecimentos a respeito do manejo das matas, sua importância para a cosmologia e a sustentabilidade. Sabedoria e classificação nativa de plantas, animais e outros seres considerados importantes nela presentes. Ervas medicinais, tipos. Coleta e usos. Melar, coletar, caçar, pescar. Propor percursos etnográficos, acompanhados por especialistas locais. Conhecimentos tradicionais - mato, identificação e caracterização dos seres da mata. Relação profunda entre vida e natureza. Ser humano na sua não separação com a natureza.

\section{Posto de saúde}

Como acontece na prática o convívio com instituições externas, em especial o posto de saúde? Acolhimento por parte da equipe? Simetrização ou hierarquização dos dois tipos de conhecimentos? São levados em consideração os aspectos das tradições indígenas, particularmente suas concepções próprias de corpo, doença e saúde? Há valorização dos conhecimentos tradicionais? Chás, por exemplo. Qual a linguagem usada nos postos indígenas pelos médicos e outros 
SERGIO BAPTISTA DA SILVA - Cartografia sociocultural de espaços e práticas educativos...

membros da equipe? Há compreensão das realidades indígenas (ausência de água potável, por exemplo)? Importância dos agentes de saúde? São valorizados (interna e externamente)? Que conhecimentos tradicionais trazem para o interior do posto de saúde? Relação mais direta e de confiança entre indígenas. Uso de uma linguagem comum, de conceitos e visões compartilhadas. Levantar aspectos sobre a hospitalização: parto, baixas e altas hospitalares. Possível uso do poder de um conhecimento que vem de fora do mundo indígena, a partir de um discurso médico? E os demais integrantes da equipe? Existência de casos variados. Equipe médica entre os Guarani do litoral, por exemplo.

Observar/registrar relatos sobre itinerários terapêuticos (as possibilidades não conflitantes de se buscar a cura a partir de variadas concepções de doença e saúde: procurar, simultaneamente, o médico, o "curandor", o xamã, o especialista em ervas, etc.).

Roteiro para observação e entrevistas: Do ponto de vista indígena, existe um ligação entre saúde, agricultura, alimentação, educação e terra?

\section{Igrejas}

Como acontece na prática o convívio com instituições externas, em particular as igrejas? Religião indígena está sendo deixada de lado? Dependência destas práticas religiosas externas ao coletivo indígena? Igrejas: que mudanças acarretam nas práticas tradicionais? Observação e entrevistas com xamãs. Observar os espaços rituais tradicionais. Igrejas e xamanismo: subordinação? Tensão entre gerações: xamãs acreditam que os jovens não respeitam seus conhecimentos?

Acesso das crianças a outras instituições: TV, posto de saúde, igrejas, etc.

\section{Escola indígena / Educação escolar indígena}

Como é percebida pelos indígenas (pais, crianças), pelos professores indígenas, pelos professores não indígenas, na escola observada? O adjetivo "diferenciada" usado após o substantivo "escola" significa reduzir os critérios de avaliação? Simplificar os conteúdos? 
SERGIO BAPTISTA DA SILVA - Cartografia sociocultural de espaços e práticas educativos...

Como o "diferenciado" é visto, entendido, pelos professores indígenas e não indígenas.

Currículo: apresenta-se adequado aos espaços educativos extraescolares? Traz para dentro da escola os conhecimentos e práticas tradicionais? Currículo mínimo.

Os calendários escolares são diferenciados? Há respeito à temporalidade do grupo? O que fazer como proposta?

Há um espaço diferenciado, intercultural, na escola indígena observada?

Qualificação dos professores indígenas. Sua formação e preparação. O que o Estado faz? Preferir professores indígenas mesmo sem formação?

Há diferenças entre as percepções de escola indígena para os Guarani e para os Kaingang?

Ensino de qualidade? O que é isso para dentro (ponto de vista nativo) e para fora (Secretaria, Coordenadorias)? Há uma desvalorização do profissional indígena em relação ao não indígena?

"Correr atrás do prejuízo"? Questões para pensar a autonomia da escola indígena. Escola integral?

Como pensar a avaliação na escola indígena? Cobrança dupla? Trabalhar com cultura indígena, língua e, além disto, corresponder às expectativas legais da legislação federal?

Criação do Conselho Estadual de Educação Indígena para normatizar a escola indígena.

Livro didático. O que faz o Estado? O que faz o corpo docente indígena e não indígena?

Trazer dados sobre a estrutura das escolas. Hierárquica? Direção não indígena.

Existem práticas pedagógicas diferenciadas? Se sim, quais? Ex.: gráficos, produção textual abordando temáticas internas, gravidez nas adolescentes indígenas, narrativas indígenas na produção textual. Há aproveitamento dos conhecimentos que vêm de casa?

Comportamento dos alunos - pouca interação, diálogo, oralidade. Relação disso com professores não indígenas nas primeiras séries.

Para pensar: Criação de Pontos de Cultura. Introdução de outras práticas. Vídeo com celular. Construção de espaços alternativos 
educativos juntamente com a escola. Dia do índio: atividades escolares extramuros.

Refletir sobre a conveniência da antecipação de conteúdos sobre corpo e sexualidade.

Escrita $X$ oralidade. Para que $(m)$ se escreve na aldeia? $O$ que se escreve na aldeia? Em que língua?

\section{Rio}

Espaço de saberes (nadar, pescar, conhecimentos envolvendo os seres que o habitam, ou suas margens). Espaço de brincadeiras.

\section{Terra indígena}

Como se realiza e atualiza a cultura indígena e seus espaços educativos em uma terra homologada?

\section{Acampamento}

Como se realiza e atualiza a cultura indígena e seus espaços educativos em uma terra sem garantias de direito?

\section{Roça}

O trabalhar juntos. A reciprocidade, a ajuda mútua.

\section{Fogo}

Espaço de oralidade. Narrativas e ensinamentos ao redor do fogo. O fogo como espaço de transformação.

\section{Cemitério}

Pesquisar sobre concepções de doença, morte. O sistema xamânico-cosmológico do coletivo indígena trabalhado. Conceitos de corpo e pessoa. 
SERGIO BAPTISTA DA SILVA - Cartografia sociocultural de espaços e práticas educativos...

\section{Espaços educativos políticos: internos e externos}

Investigar sobre sua presença ou ausência. Sua constituição, atuação e importância.

\subsubsection{Algumas práticas educativas:}

1.1.2.1. Narrativas. Mitos;

1.1.2.2. Memória sociocultural;

1.1.2.3. Rituais; os espaços rituais e festivos e sua relação com a música e a dança;

1.1.2.4. Nominação das crianças;

1.1.2.5. Tradição Oral - oralidade

\subsection{Processos de Educação Escolar e Histórias da Educação Escolar em Terras Indígenas}

Histórico da implantação da escola na TI. Caracterizar o processo.

Algumas trajetórias de ex-aluno(a)s; seus processos de escolarização.

Ligação da história da escola nas áreas indígenas investigadas e os variados processos históricos (Lei de Terras, Ocupação das terras indígenas, os diversos governos estaduais e federais e suas influências, etc.).

Bilinguismo. SIL (Summer Institute of Linguistics). Mudanças. Denúncias contra SPI.

Escola hoje: sua estrutura, hierarquia, funcionamento, corpo docente e discente. Professores indígenas e não indígenas. Inclusão de dados quantitativos e qualitativos.

\section{Comentários finais e desafios futuros}

Fundamentalmente, o trabalho apresentado pretende contribuir, na prática, para o registro, visibilização e valorização de saberes 
SERGIO BAPTISTA DA SILVA - Cartografia sociocultural de espaços e práticas educativos...

indígenas presentes em espaços e práticas educativos indígenas não completamente compreendidos e, menos ainda, legitimados nos processos escolares. Para tanto, ficam disponíveis os instrumentos metodológicos propostos como modo de cartografá-los e entendê-los como expressões socio-cosmo-ontológicas específicas destes coletivos.

Penso que a compreensão e legitimação destas lógicas são passos importantes para a implementação de direitos vários, não só com relação a uma educação intercultural e na simetrização dos processos escolares, mas, igualmente, na obtenção e qualificação de direitos territoriais, de atenção à saúde, entre tantos.

Um dos desafios que permanece em aberto é o de criar mecanismos que visibilizem estas lógicas, que institucionalizem estes direitos e que efetivamente indigenizem a escola.

Igualmente, tem-se a questão da permanência escolar dos estudantes indígenas, em todos os níveis. Para além dos desafios do acesso, sobre manutenção, sobre bolsas, moradia e acompanhamento, gostaria de enfatizar os desafios relacionados às especificidades dos processos educativos indígenas e valorização de suas lógicas, e o que isso significa para a permanência indígena nos diferentes níveis escolares.

Como disseram nossos interlocutores indígenas neste empreendimento coletivo e participativo relatado, a indigenização da escola está relacionada ao ato de cartografar os espaços e práticas educativos indígenas e articulá-los simetricamente à escola.

\section{Referências bibliográficas}

BAPTISTA DA SILVA, Sergio. Dualismo e cosmologia kaingang: o xamã e o domínio da floresta. Horizontes Antropológicos, Porto Alegre, v. 8, n. 18, p. 189-209, dez. 2002. Disponível em: http://www.scielo.br/scielo.php?script=sci_arttext\&pid=S010471832002000200009\&lng=pt\&nrm=iso . Acesso em: 28 dez. 2013.

Cosmo-ontológica mbyá-guarani: discutindo o estatuto de "objetos" e "recursos naturais". Revista de Arqueologia, São Paulo, v. 26, n. 1, p. 42-55, 2013.

CARNEIRO, Leonardo Garcia. "Posso ser o que você é sem deixar de ser o que sou!": a

Espaço Ameríndio, Porto Alegre, v. 7, n. 2, p. 227-238, jul./dez. 2013. 
SERGIO BAPTISTA DA SILVA - Cartografia sociocultural de espaços e práticas educativos...

presença de estudantes indígenas na UFRGS - perspectivas para pensar a indigenização da "modernidade". 2013. 63 f. Monografia (Bacharelado em Ciências Sociais) UFRGS, Porto Alegre, 2013.

ROSA, Rogério G.; NUNES, Rojane B. Educação Escolar Indígena e/ou Educação Indígena: questões e possibilidades para kainganguizar a escola. Século XXI, Santa Maria, v. 3, p. 62-87, 2013.

SAHLINS, Marshall. O "pessimismo sentimental" e a experiência etnográfica: por que a cultura não é um "objeto" em via de extinção (parte I). Mana, Rio de Janeiro, v. 3, n. 1, p. 41-73, 1997a. Disponível em: http://www.scielo.br/scielo.php?script=sci_arttext\&pid=S0104-

93131997000100002\&lng=en\&nrm=iso . Acesso em: 28 dez. 2013.

O "pessimismo sentimental" e a experiência etnográfica: por que a cultura não é um "objeto" em via de extinção (parte II). Mana, Rio de Janeiro, v. 3, n. 2, p. 103 150, 1997b. Disponível em: http://www.scielo.br/scielo.php?script=sci_arttext\&pid=S010493131997000200004\&lng=en\&nrm=iso . Acesso em: 28 dez. 2013. 